\title{
Community-acquired pneumonia in elderly patients
}

\author{
John E Stupka, MD, \\ The University of Texas Health Science Center at San Antonio, Department of Medicine, Division \\ of Pulmonary \& Critical Care Medicine, San Antonio, TX, USA, Tel.: +1 210617 5256, Fax: +1 \\ 210567 4423, stupka@uthscsa.edu \\ Eric M Mortensen, MD, MSc, \\ The University of Texas Health Science Center at San Antonio, Department of Medicine, Division \\ of General Medicine, San Antonio, TX, USA and VERDICT (11C6) at the South Texas Veterans \\ Health Care System, Audie L Murphy Division, San Antonio, TX, USA, Tel.: +1210617 5300, \\ Fax: +1 210567 4423, mortensene@uthscsa.edu
}

Antonio Anzueto, MD, and The University of Texas Health Science Center at San Antonio, Department of Medicine, Division of Pulmonary \& Critical Care Medicine, San Antonio, TX, USA and South Texas Veterans Health Care System, Audie L Murphy Division, TX, USA, Tel.: +1 210617 5256, Fax: +1 210567 4423, anzueto@uthscsa.edu

Marcos I Restrepo, MD, MSc ${ }^{\dagger}$

The University of Texas Health Science Center at San Antonio, Department of Medicine, Division of Pulmonary \& Critical Care Medicine, San Antonio, TX, USA and VERDICT (11C6) at the South Texas Veterans Health Care System, Audie L Murphy Division, San Antonio, TX, USA, Tel.: +1 2106175300 ext. 15413, Fax: +1 210567 4423, restrepom@uthscsa.edu

\section{Abstract}

Community-acquired pneumonia continues to have a significant impact on elderly individuals, who are affected more frequently and with more severe consequences than younger populations. As the population ages it is expected that the medical and economic impact of this disease will increase. Despite these concerns, little progress has been made in research specifically focusing on community-acquired pneumonia in the elderly. Data continue to show that a high index of suspicion, early antimicrobial therapy and appropriate medications to cover typical pathogens are extremely important in treating community-acquired pneumonia in older individuals. This review is designed to serve as an update to our previous work published in Aging Health in 2006, with specific emphasis on the most recent evidence published since that time.

\footnotetext{
${ }^{\dagger}$ Author for correspondence VERDICT (11C6) at the South Texas Veterans Health Care System ALMD, 7400 Merton Minter Boulevard, San Antonio, TX 78229, USA, Tel.: +1 2106175300 ext. 15413, Fax: +1 210567 4423, restrepom@uthscsa.edu. Financial \& competing interests disclosure

Antonio Anzueto has served in the speaker's bureaus of Pfizer, Boehringer Ingelheim, GlaxoSmithKline, Astra-Zeneca; OrthoMcNeil-Janssen, Johnson \& Johnson; Bayer-Schering Pharma, Schering-Plough; in the advisory board of GlaxoSmithKline, Boehringer Ingelheim, Bayer-Schering Pharma, Schering-Plough and Pfizer; and is the principal investigator on research grants that were awarded to the University of Texas Health Science Center at San Antonio by GlaxoSmithKline, Pfizer and Lilly Pharma. Marcos I Restrepo has worked for the Speakers Bureaus of Ortho-McNeil-Janssen, Johnson \& Johnson, Pfizer, Covidien and BARD, Inc., and is on the Advisory Boards for Ortho-McNeil-Janssen, Johnson \& Johnson. Restrepo is supported by a Department of Veteran Affairs Veterans Integrated Service Network 17 new faculty grant and a CTSA Award Number (KL2 RR025766).

The authors have no other relevant affiliations or financial involvement with any organization or entity with a financial interest in or financial conflict with the subject matter or materials discussed in the manuscript apart from those disclosed.

No writing assistance was utilized in the production of this manuscript.
} 


\section{Keywords}

aged; microbiology; pneumonia; severity of illness index; therapeutics

Despite widespread availability of antibiotic therapy and sophisticated severity of illness assessments, community-acquired pneumonia (CAP) continues to be a leading cause of death worldwide. In the elderly population, defined as those aged over 65 years, the impact of pneumonia is far greater than in other age groups. The annual incidence of pneumonia in the elderly is four-times that of younger populations [1]. In addition, older adults have higher rates of hospitalization and are more likely to die as a result of CAP [2,3]. The elderly population is increasing at twice the rate of the general population, necessitating a better understanding of the pathophysiology, microbiology, treatment and prevention of this common affliction.

The mechanisms behind the disproportionate incidence and mortality rates in elderly pneumonia patients are not fully understood. Several physiologic changes in older adults have been implicated as risk factors for CAP. Changes in basic lung physiology as a result of aging include decreased elastic recoil, increased air trapping (senile emphysema), decreased chest wall compliance and reduced respiratory muscle strength [4]. These factors may act to increase baseline work of breathing, giving older individuals less reserve to cope with bacterial infections in the lung. In addition, reduced mucocilliary clearance and diminished cough reflex have been described [5,6]. These findings, combined with greater upper airway colonization with virulent organisms, may predispose this population to develop lower respiratory tract infections [7]. One small study supports this theory, demonstrating an increased incidence of silent aspiration in elderly adults with CAP [8]. Changes in the immune system with aging have also been postulated, although this remains a controversial area. Immune senescence has long been described in animal and human studies [9]. The effects of aging on the immune system are thought to include decreased cell-mediated and humoral immunity [1,10]. These findings are challenged by more recent data, which reveal that elderly pneumonia patients have similar severity of illness scores and equal cytokine responses, suggesting that immune responses may not be blunted in older populations [11].

One widely accepted explanation for the increased incidence and severity of CAP in this age group involves the presence of multiple comorbidities. Kothe et al. demonstrated that comorbid illnesses (including congestive heart failure, cerebrovascular disease and chronic liver disease) were independent risk factors for increased 30-day mortality [12]. Regarding the etiology of pneumonia, several studies have documented that the etiology of CAP in elderly patients does not differ significantly from younger populations $[1,13]$. However, elderly patients may present differently than other age groups [14].

While the exact cause is not yet clear, the data clearly support that CAP affects elderly patients at higher rates and results in higher mortality. The focus of this article is to review the most recent data regarding the epidemiology, microbiology, diagnosis, treatment and prevention of CAP in elderly populations.

\section{Epidemiology}

In the elderly population, CAP remains the single most common cause of death from infectious diseases [15]. Adults aged over 65 years are a rapidly expanding cohort with growth rates more than twice that of younger populations. With an expected $20 \%$ of the world's population reaching elderly status by 2050 , the burden of CAP will be even more significant in the coming years [16]. The annual incidence of CAP in elderly patients is 
estimated to be 25-44 cases per 1000 persons [1]. A recent large, population-based cohort study of elderly adults by Jackson et al. further divided this population into two groups, those aged 65-69 years and those aged 85 years and older [17]. This study, which examined both inpatient and outpatient episodes of CAP found incidence rates of 18.2 cases per 1000 persons in the 65-69-year-olds group and 52.3 cases per 1000 persons in those aged at least 85 years [17]. This data suggests that even within the elderly population, those with more advanced age are more susceptible to CAP.

The data for hospitalization rates are equally impressive, as elderly patients are almost fivetimes more likely to be hospitalized with the disease. In an observational cohort study of 623,718 Medicare patients aged 65 years or older, Kaplan et al. found that elderly patients were hospitalized at a rate of 18.3 per 1000 cases of CAP [2]. In the same study, the investigators found hospitalization rates of four per 1000 cases in younger populations [2]. Just as incidence rates appear to increase with age in the elderly population, rates of hospitalization rise with advancing age. In the Kaplan study, adults older than 90 years of age were over five-times more likely to be hospitalized than those aged 65-69 years [2].

Mortality rates in the elderly with CAP are higher than in younger populations. The most recent data revealed mortality rates ranging from 10 to $30 \%$ in those aged 65 years or older $[1,12]$. In a matched case-control database of Medicare patients, Kaplan and collaborators found an inpatient death rate of $12 \%$ and a 1 -year mortality of more than $40 \%$ in elderly adults with CAP [18]. A recent study by Kothe et al. confirms these findings, demonstrating that age itself was associated with increased mortality in CAP [12]. Furthermore, mortality is higher among older adults with CAP when compared with age-matched controls without the disease. Hospitalized age-matched controls without CAP have mortality rates almost $12 \%$ lower than those with pneumonia [18]. It is unclear if these findings are due to the pneumonia itself or if CAP serves as a marker of illness in older populations. Several studies have attempted to identify risk factors for developing CAP in this age group. A populationbased cohort study of 46,237 elderly patients found that chronic obstructive pulmonary disease (COPD), immunosuppression, smoking, congestive heart failure, diabetes, malignancy and previous hospitalizations for CAP were independent risk factors for developing the disease [17]. Risk factors for mortality in CAP have also been evaluated. The Community-acquired Pneumonia Competence Network (CAPNETZ) study included a subset of 1349 patients aged 65 years or older [12]. The investigators found that comorbid illness (including congestive heart failure, cerebrovascular disease and chronic liver disease), higher CURB scores (see Box 1) and ineffective therapy were associated with higher mortality from CAP among the elderly [12]. Additional studies have identified other factors linked to increased mortality in this cohort including delirium, bedridden status, absence of fever, tachypnea, C-reactive protein levels greater than $100 \mathrm{mg} / \mathrm{l}$, hypoalbuminemia, acute organ dysfunction, suspicion of aspiration and swallowing disorders [1].

\section{Microbiology}

As with any infectious disease, identifying the causative agent in CAP can be extremely useful in guiding antimicrobial therapy. Unfortunately, the diagnostic yield of sputum samples in this age group has historically been very low. In at least $40-60 \%$ of all CAP cases a microbiologic diagnosis cannot be made [4]. Some studies have reported that causative organisms are only identified in 5-20\% of CAP cases in the elderly $[12,16]$. In a recent multicenter prospective study, valid sputum samples were collected in $43.1 \%$ of elderly patients, compared with $56.5 \%$ in younger subjects [12]. Difficulty expectorating sputum, early use of empiric antibiotics and reduced ability to comply with sample acquisition have been cited as possible reasons $[4,16]$. In the same study bronchoscopic 
evaluation and thoracentesis were less commonly performed in elderly patients with CAP, perhaps indicating a reluctance to perform invasive diagnostic procedures in older patients.

In most cases, the microbiologic patterns observed in the elderly do not differ significantly from those observed in younger populations (Table 1). Streptococcus pneumoniae remains the single most common organism identified in hospitalized elderly patients with CAP, accounting for $19-58 \%$ of cases based on available data [1,5]. In all studies reviewed, $S$. pneumoniae was the most common organism identified. Haemophilus influenzae was also frequently isolated, accounting for $5-14 \%$ of CAP in the elderly population $[4,14,16]$. Infection with this organism may be more common in patients with chronic obstructive lung disease. Moraxella catarrhalis and Staphylococcus aureus (primarily methicillin sensitive) have also been described as pathogens, with frequencies up to 4 and $7 \%$, respectively [1].

The recent emergence of community-associated methicillin-resistant S. aureus (CA-MRSA) in younger populations raises concern for infection in older adults. The available data suggest that elderly adults are less commonly affected [19]. Nevertheless, the astonishing virulence of this organism makes CA-MRSA a grave concern in the vulnerable elderly population. Further studies are necessary to determine if the elderly will be increasingly affected by this growing epidemic. As with younger populations, in elderly adults with influenza, such as prodromes, skin lesions, cavitary infiltrates, hemoptysis or rapidly progressing pneumonias, CA-MRSA should be considered as a causative agent [19].

Infections with Gram-negative bacteria are often related to comorbid illnesses, thus one would expect that elderly patients are more likely to succumb to these organisms. While elderly nursing-home residents and hospitalized patients frequently present with Gramnegative pneumonias, these infections are an infrequent cause of CAP in the elderly [1]. A study by Fernandez-Sabe et al. highlights this point, demonstrating that Gram-negative bacilli were only seen in 3\% of CAPs in patients aged over 80 years [14]. This figure is only slightly higher than reported rates in younger populations, indicating that Gram-negative organisms are an uncommon cause of CAP in any age group. However, in severely debilitated or chronically ill elderly patients from the community, a high index of suspicion for Gram-negative bacilli may be warranted, especially in those who fail to improve on standard therapy [1]. In addition, patients with bronchiectasis may be more susceptible to Pseudomonas species, although no prospective data exists to support empiric coverage for this organism in elderly patients presenting with CAP.

Atypical organisms are less frequently found in those aged over 65 years when compared with younger populations [4]. Nevertheless, these organisms play a significant role in elderly patients with CAP. Among the atypical bacteria, Chlamydophila pneumoniae is the most common agent, with rates of 16-28\% of cases reported in the elderly [16]. Mycoplasma pneumoniae is less frequently associated with CAP in this age group (0-13\%) and Coxiella burnetii is a rare causative agent $[1,16]$. Reports regarding Legionella pneumophila in the elderly vary widely in the literature. Although relatively uncommon, it should be considered in elderly adults presenting with atypical symptoms (e.g., headache, weakness, altered mental status, gastrointestinal disturbances or bradycardia in the setting of a paucity of respiratory symptoms) $[1,14,20]$. One study of elderly patients admitted to the intensive care unit (ICU) found that $60 \%$ of patients with Legionella pneumonia had been treated with long-term corticosteroids [21]. This study suggested that immunosuppresed patients or those with severe pneumonia are more likely to be infected with L. pneumophila. Based on current microbiological data, it appears to be reasonable to exclude Legionella infection with urinary antigen testing in all elderly CAP patients before atypical coverage is discontinued. 
Influenza A or B, parainfluenza and respiratory syncytial viruses (RSV) are other etiologic agents to be considered in this population [22]. The current influenza (H1N1 influenza) pandemic has raised awareness for these infections and routine influenza screening appears to be prudent in any elderly patient presenting with a pneumonia-like illness. However, it should be noted that the sensitivity of available screening tests is poor, and clinical treatment decisions should not be based solely on the results of rapid flu testing [23]. It is our practice to screen all elderly patients with severe pneumonia for influenza, parainfluenza and RSV, although this practice is not evidence based.

\section{Box 1. Common stratification scores to assess severity and need for hospitalization in patients with community-acquired pneumonia}

\section{Pneumonia severity index score}

- A total of 20 parameters are evaluated at the time of clinical presentation and consist of:

- Three demographics (age [1 point per year of age], females [-10 points] and nursing-home resident [+10 points]);

- Five comorbid conditions (neoplasia [+30 points], liver disease [+20 points], congestive heart failure [+10 points], cerebrovascular disease [ +10 points $]$ and renal disease $[+10$ points $]$ );

- Five physical examination findings (confusion [+20 points], tachypnea [ +20 points], hypotension $[+20$ points], temperature [ +15 points $]$ and tachycardia [+15 points]);

- Seven laboratory/imaging variables (arterial $\mathrm{pH}[+30$ points], elevated blood urea [+20 points], hyponatremia [+20 points], hyperglycemia $[+10$ points], anemia by hematocrit $[+10$ points], pleural effusion $[+10$ points] and poor oxygenation $[+10$ points]).

\section{CURB-65}

- Confusion (altered mental status; 1 point)

- Urea nitrogen in serum $>19.6 \mathrm{mg} / \mathrm{dl}$ ( 1 point)

- Respiratory rate $>30$ breaths per min (1 point)

- Blood pressure (BP minus systolic BP $<90 \mathrm{mmHg}$ or diastolic $\mathrm{BP}<60 \mathrm{mmHg} ; 1$ point)

- $\quad$ Age of 65 years or older (1 point)

Pneumonia severity index score [25] and CURB-65 [26,27].

BP: Blood pressure; CURB: Confusion, urea nitrogen, respiratory rate, blood pressure and age of 65 years or older.

\section{Severity assessment \& criteria for intensive care unit admission}

Severity assessment and site-of-care decisions are critical when managing elderly patients who present with CAP. These factors have a significant impact on healthcare utilization and often affect diagnostic work-ups, therapeutic interventions and clinical outcomes. As a result, there has been significant interest in this area of research over the past decade. Severity assessment tools can help predict mortality and determine the optimal setting in which to provide care for patients with CAP. The pneumonia severity of illness (PSI) score and the CURB-65 are the most extensively studied and widely recommended scores for 
assessing patients who present with CAP (Box 1, Table 2) [24-26]. The PSI is based on 20 parameters that are evaluated at the time of clinical presentation (three demographic considerations, five comorbid conditions, five physical examination findings and seven laboratory/ imaging variables) [25]. The primary purpose of the PSI score is to distinguish between patients that could be safely treated in an outpatient setting versus those inpatient observation and treatment. Age is one of the most influential factors included in the PSI score, as every year of age in a male patient with CAP confers one point to the total severity score. For example, a male who is 80 years of age will have a PSI score of 80 points based on age alone, placing the patient in risk class III even before other variables are considered. The CURB-65 score places similar importance on age when assessing severity of illness. The CURB-65, a less complex scoring system, only requires six variables to be evaluated at presentation (confusion, blood urea nitrogen, respiratory rate, systolic or diastolic blood pressure, and age) (Box 1,Table 2) [26,27]. A simplified tool derived from the CURB-65 withdraws the only laboratory value needed to calculate the score (blood urea nitrogen). This tool, termed CRB-65, showed similar results in evaluating severity of illness in CAP [27]. In both CURB-65 and CRB-65, age is an extremely significant variable that often results in higher severity indices among elderly patients presenting with CAP. The profound influence of age on PSI, CURB-65 and CRB-65 scores highlights the fact that elderly patients with CAP are at risk for higher severity of disease and therefore poorer clinical outcomes. As always, the use of the clinician experience and clinical judgment is always recommended in addition to objective criteria such as age [28].

Several tools have also been designed to predict the need for ICU admission and the risk of death in patients presenting with severe CAP. Examples include the PS-CURXO80, SMART-COP and PIRO-CAP scores (see Table 3 for full description of scores). All of these scores, except the one recommended by the guidelines, include age as one of the variables associated with poor outcomes [24,29-31]. España and colleagues developed the PSCURXO80 system, a validated clinical prediction rule to assess the diagnosis of severe CAP with one major criterion or two or minor criteria (CURXO80) (Table 3) [29]. This assessment uses age above 80 years old as one of the minor criterion for determining severity of illness [29]. Charles et al. developed the SMART-COP scoring system, which is designed to predict the need for intensive respiratory and vasopressor support (Table 3) [30]. In this score, age is not one of the severity markers, but instead is used as an adjustment tool for two of the criterion used in the score (tachypnea and poor oxygenation). Recently, Rello and collaborators developed the CAP-PIRO score (Table 3), based on a score initially used to predict the risk of sepsis, and was able to consistently predict ICU mortality and healthcare utilization in a cohort of 529 patients admitted to the ICU with CAP [31]. This score evaluates variables related to the PIRO score that include: predisposition, infection, response and organ dysfunction, in which age greater than 70 years confers one point for each of the predisposition variables. Thus, data from the most recent severity of illness assessments support the assumption that elderly patients are at increased risk for severe CAP.

The most recent Infectious Diseases Society of America (IDSA)/American Thoracic Society (ATS) CAP 2007 guidelines define severe CAP based on at least one of the major criteria (e.g., mechanical ventilation with endotracheal intubation and/or septic shock requiring vasopressors) or at least three of the nine minor criteria (Table 3) [24]. Surprisingly, none of the major or minor criteria included age.

In conclusion, we favor the use of the CURB-65 in order to decide when to admit a patient to the hospital and the IDSA/ATS guidelines major and minor criteria to assist in the decision to admit a patient to the ICU. 


\section{Therapeutic strategies to manage CAP in elderly patients}

Antimicrobials are the cornerstone of therapy for CAP in any population, including the elderly. In addition, some nonantibiotic strategies may be important when treating CAP in elderly populations. In older patients, the pneumonia process often extends beyond the lung parenchyma, presenting as a systemic disease with higher severity of illness. This is supported by the finding that many elderly CAP patients present with primarily nonpulmonary symptoms, such as mental status changes or renal dysfunction. Owing to this fact, the following discussion will focus on both the antibiotic and nonantibiotic therapies for elderly patients with CAP. The therapeutic strategies reviewed next are an update from our prior work published in Aging Health, and the discussion is designed to serve as a review of the most relevant literature since the initial publication in 2006 [5].

\section{Antibiotic therapies}

The treatment of pneumonia in the elderly is clearly based on the use of antibiotic therapy, but limited data are available regarding the specific treatments for elderly patients with CAP. Therefore, we will attempt to summarize the most relevant and critical data published in this specific age group. The most recently published clinical practice guidelines do not recommend different treatments for elderly patients, who are included in the general treatment recommendations for CAP [24]. Our group supports the current guidelines, with specific caveats based on the recent data regarding the management of elderly with CAP.

The most recent clinical practice guidelines emphasize the importance of appropriate, aggressive and early treatment of elderly patients with CAP [24]. The latest guidelines suggest that the treatment approach should be stratified according to the location of therapy in the hospital, whether in the ward service or the ICU setting [24]. Therefore, elderly patients admitted to the ward should be covered with antimicrobial therapy that will cover the most likely pathogens, such as $S$. pneumoniae, $H$. influenzae, M. pneumoniae and $C$. pneumoniae. The treatment should include a respiratory fluoroquinolone (levofloxacin or moxifloxacin) as monotherapy or the combination of a $\beta$-lactamic (third-generation cephalosporin, ertapenem or ampicillin/sulbactam) medication and a macrolide (azithromycin or clarithromycin). In addition to the pathogens usually present in the ward service, elderly patients admitted to the ICU should be evaluated for risk of infection with Pseudomonas species. The most commonly accepted risk factor for Pseudomonas species is structural lung diseases (e.g., bronchiectasis). Those elderly ICU patients without pseudomonas risk factors should be treated with a $\beta$-lactam and the addition of an antibiotic with good atypical coverage (particularly for Legionella species), such as macrolides or respiratory fluoroquinolones. However, if Pseudomonas pneumonia is considered likely, empiric coverage should focus on its treatment without loosing coverage for Legionella and Pneumococcus. The recommended treatment in this setting includes empiric antibiotic therapy with an antipseudomonal $\beta$-lactam plus an antipseudomonal fluoroquinolone. The use of an antipseudomonal $\beta$-lactam and a macrolide is also acceptable empiric therapy, but double covering for Pseudomonas with an antipseudomonal aminoglycoside is warranted in severe infections. Aminoglycosides are not particularly good for lung infections in elderly patients owing to the risks of nephrotoxicity and ototoxicity, but are advised in critically ill patients with risk factors for Pseudomonas pneumonia. As with all infections, specific therapy should be tailored as specific pathogens are isolated. This point is even more important in elderly patients who may be at increased risk for medication interactions and adverse medication effects.

To our knowledge, only a few studies have been published since 2006 regarding the treatment of elderly patients with CAP. Anzueto and colleagues conducted a randomized, controlled trial comparing moxifloxacin $(n=195)$ versus levofloxacin $(n=199)$ in 
hospitalized elderly patients ( $\geq 65$ years) [32]. The authors concluded that moxifloxacin therapy was as efficacious (clinical cure rate $\geq 90 \%$ in all severity and age subgroups) and as safe as levofloxacin in elderly patients with CAP. The same cohort was used by Morganroth et al. who compared the cardiac rhythm safety of these two medications and the impact on QTc interval prolongation. The results demonstrated that moxifloxacin was as safe as levofloxacin, and the QTc interval prolongation was not different among groups, even in high-risk elderly patients with CAP [33]. Nonetheless, caution must be exercised when using any fluoroquinolone or macrolide in patients with known prolongation of the QT interval, hypokalemia, hypomagnesaemia and patients receiving class IA (e.g., quinidine and procainamide) or class III (e.g., amiodarone and sotalol) antiarrhythmic agents [34]. Most of the other studies comparing specific antibiotic therapies have been published prior to 2006 and are extensively reviewed in our prior publication [5,35-38].

Empiric antibiotic therapy focusing on CA-MRSA is still not consistently recommended by the latest clinical practice guidelines, but there is a great concern regarding the higher incidence of CA-MRSA reported in the community $[19,24]$. In addition, the association of CA-MRSA and influenza raises concern for the need of empiric therapy in certain situations; however, more data are needed to draw firm conclusions. At this point, the authors recommend considering CA-MRSA pneumonia coverage in patients that present with the following risk-factors: rapid presentation and progression of a cavitating pneumonia, high severity of disease, associated influenza infection or associated skin lesions consistent with MRSA infections. In these settings, coverage should include empiric vancomycin or linezolid, with the possibility that linezolid may be more appropriate coverage owing to inhibition of toxin production and increasing vancomycin minimum inhibitory concentrations among MRSA isolates [19,24].

Recent data suggested that combination therapy with a $\beta$-lactam and a macrolide was associated with favorable outcomes in hospitalized and ICU patients with CAP [39-45] and bacteremic pneumococcal pneumonia [40,41,46-48]. The beneficial effect observed with the macrolides may be owing to their immunomodulatory properties, but more data are needed to support this hypothesis. Most of the data are limited to few randomized, controlled trials and observational studies with significant heterogeneity. Therefore, our group suggests clinicians to follow the latest clinical practice guideline recommendations [24], owing to the significant number of studies supporting the benefit in clinical practice with improved clinical outcomes [49-57]. In addition, national practice guidelines strongly recommend that locally adapted guidelines should be implemented to improve process of care measures and important clinical outcomes. The impact of following the clinical practice guidelines for the management of CAP has shown improvement in the quality and efficiency of care, and decreased mortality [52-57].

\section{Nonantibiotic therapies}

Several nonantibiotic therapies have been recommended in severely ill patients with CAP, usually those in the ICU setting. These therapies include the use of systemic corticosteroid $[58,59]$ therapy for patients with severe CAP, recombinant human activated protein C [60] for patients with severe sepsis owing to CAP with at least two organs failing and the use of lung protective-ventilation strategy [61] for patients with acute respiratory distress syndrome owing to CAP. Although lung-protective ventilation is the standard of care in acute respiratory distress syndrome patients, the benefits of other therapies, such as corticosteroids [58,59] or activated protein C [60], are less clear in patients with severe CAP. In addition, there is a growing body of evidence suggesting that certain immunomodulatory agents other than corticosteroids may favorably influence outcomes in patients with CAP [62-65]. Such immunomodulatory agents include medications, such as statins and angiotensin-converting enzyme inhibitors, which have been suggested to improve outcomes in patients with 
pneumonia [62-65]. However, these studies were mainly retrospective in nature and the healthy-user bias was not controlled for; therefore, further prospective studies and randomized, controlled trials are needed before recommending them in clinical practice.

\section{Prevention}

Although vaccination is the mainstay of preventative therapy in elderly patients, substantial underuse of pneumococcal and influenza vaccination exists in this vulnerable population $[14,66]$. Some investigators have concluded that the efficacy of vaccination may be reduced among elderly individuals, although this point is controversial as the possible healthy-user bias effect is not controlled in most of the effectiveness studies [67-70]. However, owing to the increased incidence of CAP in elderly populations, this cohort may receive significant benefit from vaccination even in the face of decreased efficacy [1]. In accordance with the current guidelines, all individuals older than 50 years of age should receive annual influenza vaccinations during the autumn and winter. In addition, any person aged over 65 years should receive pneumococcal vaccination. The efficacy of revaccination is unknown, but those who received the vaccine prior to 65 years of age should receive an additional vaccination after 5 years [24]. Vaccination can be administered in routine outpatient settings or upon discharge in patients hospitalized for any condition. Chemoprophylaxis for influenza infection with oseltamivir or zanamivir should be considered in those who have household exposure and are at high risk for influenza complications in the setting of an outbreak. Alternatively, the most recent CDC guidelines suggest that careful monitoring for symptoms and early treatment may be an acceptable strategy in high-risk patients with close influenza contacts [101]. Although the link between pneumococcal vaccination and mortality has not been well established, vaccination has been demonstrated to reduce the risk of invasive disease in elderly individuals [16].

It is estimated that almost a third of CAP in the elderly is linked to smoking, thus smoking cessation measures are particularly important for preventing CAP in older individuals [17]. Other tactics, such as oral care and prevention of aspiration, have been studied extensively in nursing home and hospitalized patients, but further research is needed to determine if these findings can be applied to patients at risk for CAP [71-72].

\section{Executive summary}

\section{Background}

- Community-acquired pneumonia (CAP) is the fifth leading cause of death and the most common cause of death from infectious diseases in persons aged 65 years and over in the USA.

- The elderly are particularly susceptible to this infection because of their impaired gag reflex, impaired mucociliary function, declining immunity and presence of comorbid conditions.

\section{Epidemiology}

- The annual incidence of CAP for noninstitutionalized patients is estimated at 18.2 cases per 1000 persons in persons aged 65-69 years and 52.3 cases per 1000 persons in those aged 85 years and older.

- Mortality is also considerably higher in elderly patients with CAP compared with other groups.

- Immunosuppression, smoking, chronic obstructive pulmonary disease, congestive heart failure, diabetes mellitus, lung cancer, serious nonpulmonary 
malignancy and previous hospitalizations for pneumonia were all independently associated with risk of CAP patients aged 65 years and over.

\section{Etiology}

- The most common pathogen isolated in patients over 65 years with CAP is Streptococcus pneumoniae, although atypicals and Gram-negative bacilli play an important role.

\section{Severity assessment $\&$ criteria for admission to the hospital and the intensive care} unit

- The definition of severe CAP requires hospitalization on the ward service and/or intensive care unit (ICU).

- Although severity assessment criteria (pneumonia severity of illness score, CURB-65 and American Thoracic Society criteria) are useful to help identify patients who may need hospitalization in the ward service or ICU, they are not meant to replace clinical judgment.

\section{Treatment of CAP}

- Empiric antimicrobial regimens should cover S. pneumoniae with $\beta$-lactam medications or new respiratory fluoroquinolones, and atypical pathogens should be treated with macrolides or respiratory fluoroquinolones.

\section{Treatment of CAP in ward patients}

- Although not specifically validated in elderly patients, criteria for switching to oral therapy and early discharge should be considered in this patient population.

\section{Treatment for severe CAP}

- Treatment for severe CAP should always include combined antimicrobial therapy ( $\beta$-lactam plus either a macrolide or a respiratory fluoroquinolone).

- Severe CAP patients admitted to the ICU should be stratified as to whether or not the patients are at risk for Pseudomonas species infection and be treated accordingly.

\section{Duration of therapy}

- The duration of therapy in CAP patients requiring hospitalization is 7-10 days, but those with atypical pathogens such as Legionella species, should receive treatment for 10-14 days.

\section{Prevention}

- Vaccination is the mainstay for prevention of CAP.

- All persons aged 65 years and over should receive the pneumococcal polysaccharides vaccine. The efficacy of revaccination is unknown.

- All persons aged 50 years and over should receive inactivated influenza vaccine during the autumn and winter.

- Chemoprophylaxis for influenza infection with oseltamivir or zanamivir for those who have household exposure or are at high risk for influenza complications in the setting of an outbreak.

- A smoking cessation plan should be offered to all elderly smoker patients, since nearly a third of pneumonia episodes could be attributed to smoking. 


\section{Future perspective}

Considering the increased morbidity, mortality and cost associated with CAP in elderly populations, the rapid growth of persons over 65 years of age in the general population is alarming. For reasons that are not yet completely clear, elderly populations are at increased risk for acquiring respiratory infections and are more likely to suffer from severe disease. Indeed, in the next century we will see a significant increasing in the number of elderly patients with CAP. Strategies directed at improving the evaluation, diagnosis, treatment and prevention of CAP are imperative and should be specifically focused on this population. Research directed at reducing costs and limiting healthcare utilization, such as developing criteria for transition to oral antibiotics or early discharge, are of particular interest in this population.

\section{Conclusion}

CAP is the fifth leading cause of death and the most common cause of death from infectious diseases in persons aged 65 years and over in the USA, with significant impact on morbidity and mortality. As for the etiology, S. pneumoniae is still the most common pathogen, although atypical organisms and other new pathogens (e.g., CA-MRSA) play an important role. Antimicrobial selection for elderly patients with CAP does not differ from that of younger adult populations. specific emphasis should be placed on early antibiotic administration and strict adherence to the antibiotic regimes recommended in clinical practice guidelines. In addition, measures directed at prevention, such as vaccination for pneumococcal and influenza infections, and smoking cessation programs for at-risk patients may help to decrease the incidence and severity of CAP.

\section{Bibliography}

Papers of special note have been highlighted as:

- of interest

1. Janssens JP, Krause KH. Pneumonia in the very old. Lancet Infect Dis 2004;4(2):112-124. [PubMed: 14871636]

2. Kaplan V, Angus DC, Griffin MF, Clermont G, Scott Watson R, Linde-Zwirble WT. Hospitalized community-acquired pneumonia in the elderly: age- and sex-related patterns of care and outcome in the United States. Am. J. Respir. Crit Care Med 2002;165(6):766-772. [PubMed: 11897642]

3. Fine MJ, Smith MA, Carson CA, et al. Prognosis and outcomes of patients with communityacquired pneumonia. A meta-analysis. JAMA 1996;275(2):134-141. [PubMed: 8531309]

4. Chong CP, Street PR. Pneumonia $n$ the elderly: a review of the epidemiology, pathogenesis, microbiology, and clinical features. South Med. J 2008;101(11):1141-1145. quiz 32, 79. [PubMed: 19088525] Comprehensive literature review outlining the characteristics of pneumonia in elderly patients.

5. Velez JA, Mortensen EM, Anzueto A, Restrepo MI. Antimicrobial treatment of communityacquired pneumonia in the elderly. Aging Health 2006;2(6):999-1011.

6. Ho JC, Chan KN, Hu WH, et al. The effect of aging on nasal mucociliary clearance, beat frequency, and ultrastructure of respiratory cilia. Am. J. Respir. Crit. Care Med 2001;163(4):983-988. [PubMed: 11282777]

7. Valenti WM, Trudell RG, Bentley DW. Factors predisposing to oropharyngeal colonization with Gram-negative bacilli in the aged. N. Engl. J. Med 1978;298(20):1108-1111. [PubMed: 643028]

8. Kikuchi R, Watabe N, Konno T, Mishina N, Sekizawa K, Sasaki H. High incidence of silent aspiration in elderly patients with community-acquired pneumonia. Am. J. Respir. Crit. Care Med 1994;150(1):251-253. [PubMed: 8025758] 
9. Castle SC. Clinical relevance of age-related immune dysfunction. Clin. Infect. Dis 2000;31(2):578585. [PubMed: 10987724]

10. Meyer KC. The role of immunity in susceptibility to respiratory infection in the aging lung. Respir. Physiol 2001;128(1):23-31. [PubMed: 11535259]

11. Kelly E, MacRedmond RE, Cullen G, Greene CM, McElvaney NG, O’Neill SJ. Communityacquired pneumonia in older patients: does age influence systemic cytokine levels in communityacquired pneumonia? Respirology 2009;14(2):210-216. [PubMed: 19272082] Prospective observational study suggesting that elderly patients have similar cytokine responses to communityacquired pneumonia (CAP) when compared with younger cohorts.

12. Kothe H, Bauer T, Marre R, Suttorp N, Welte T, Dalhoff K. Outcome of community-acquired pneumonia: influence of age, residence status and antimicrobial treatment. Eur. Respir. J 2008;32(1):139-146. [PubMed: 18287129] Multicenter, prospective study focusing on clinical history, residence status, course of disease and antimicrobial treatment in elderly patients with CAP.

13. Ruiz M, Ewig S, Marcos MA, et al. Etiology of community-acquired pneumonia: impact of age, comorbidity, and severity. Am. J. Respir. Crit. Care Med 1999;160(2):397-405. [PubMed: 10430704]

14. Fernandez-Sabe N, Carratala J, Roson B, et al. Community-acquired pneumonia in very elderly patients: causative organisms, clinical characteristics, and outcomes. Medicine (Baltimore) 2003;82(3):159-169. [PubMed: 12792302]

15. Hoyert DL, Kung HC, Smith BL. Deaths preliminary data for 2003. Natl Vital Stat. Rep 2005;53(15):1-48.

16. Donowitz GR, Cox HL. Bacterial community-acquired pneumonia in older patients. Clin. Geriatr. Med 2007;23(3):515-534. VI. [PubMed: 17631231] Review highlighting key aspects of CAP in elderly patients.

17. Jackson ML, Neuzil KM, Thompson WW, et al. The burden of community-acquired pneumonia in seniors: results of a population-based study. Clin. Infect. Dis 2004;39(11):1642-1650. [PubMed: 15578365]

18. Kaplan V, Clermont G, Griffin MF, et al. Pneumonia: still the old man's friend? Arch. Intern. Med 2003;163(3):317-323. [PubMed: 12578512]

19. Hidron AI, Low CE, Honing EG, Blumberg HM. Emergence of community-acquired methicillinresistant Staphylococcus aureus strain USA300 as a cause of necrotising community-onset pneumonia. Lancet Infect. Dis 2009;9(6):384-392. [PubMed: 19467478]

20. Finegold SM. Legionnaires' disease - still with us. N. Engl. J. Med 1988;318(9):571-573. [PubMed: 3340137]

21. Macfarlane JT, Miller AC, Roderick Smith WH, Morris AH, Rose DH. Comparative radiographic features of community acquired Legionnaires' disease, pneumococcal pneumonia, mycoplasma pneumonia, and psittacosis. Thorax 1984;39(1):28-33. [PubMed: 6695350]

22. Andrews J, Nadjm B, Gant V, Shetty N. Community-acquired pneumonia. Curr. Opin. Pulm. Med 2003;9(3):175-180. [PubMed: 12682561]

23. Faix DJ, Sherman SS, Waterman SH. Rapid-test sensitivity for novel swine-origin influenza A (H1N1) virus in humans. N Engl. J. Med 2009;361(7):728-729. [PubMed: 19564634]

24. Mandell LA, Wunderink RG, Anzueto A, et al. Infectious Diseases Society of America/American Thoracic Society consensus guidelines on the management of community-acquired pneumonia in adults. Clin. Infect. Dis 2007;44 Suppl. 2:S27-S72. [PubMed: 17278083]

25. Fine MJ, Auble TE, Yealy DM, et al. A prediction rule to identify low-risk patients with community-acquired pneumonia. N. Engl. J. Med 1997;336(4):243-250. [PubMed: 8995086]

26. Lim WS, Lewis S, Macfarlane JT. Severity prediction rules in community acquired pneumonia: a validation study. Thorax 2000;55(3):219-223. [PubMed: 10679541]

27. Lim WS, van der Eerden MM, Laing R, et al. Defining community acquired pneumonia severity on presentation to hospital: an international derivation and validation study. Thorax 2003;58(5): 377-382. [PubMed: 12728155]

28. Metlay JP, Fine MJ. Testing strategies in the initial management of patients with communityacquired pneumonia. Ann. Intern. Med 2003;138(2):109-118. [PubMed: 12529093] 
29. Espana PP, Alberto C, Inmaculada G, Cristobal E, Mikel O, Miguel O. Development and validation of a clinical prediction rule for severe community-acquired pneumonia. Am. J. Respir. Crit. Care Med 2006;174(11):1249. [PubMed: 16973986] Multivariate analysis identifying eight independent factors that predict severe CAP.

30. Charles PG, Wolfe R, Whitby M, et al. SMART-COP: a tool for predicting the need for intensive respiratory or vasopressor support in community-acquired pneumonia. Clin. Infect. Dis 2008;47(3):375-384. [PubMed: 18558884] Prospective study focusing on a tool for predicting the need for intensive respiratory or vasopressor support in patients with CAP.

31. Rello J, Rodriguez A, Lisboa T, Gallego M, Lujan M, Wunderink R. PIRO score for communityacquired pneumonia: a new prediction rule for assessment of severity in intensive care unit patients with community-acquired pneumonia. Crit. Care Med 2009;37(2):456-462. [PubMed: 19114916] Prospective, observational, cohort study designed to develop a severity assessment tool to predict mortality in CAP patients in the intensive care unit.

32. Anzueto A, Niederman MS, Pearle J, et al. Community-Acquired Pneumonia Recovery in the Elderly (CAPRIE):efficacy and safety of moxifloxacin therapy versus that of levofloxacin therapy. Clin. Infect. Dis 2006;42(1):73-81. [PubMed: 16323095]

33. Morganroth J, Dimarco JP, Anzueto A, Niederman MS, Choudhri S, Group CS. A randomized trial comparing the cardiac rhythm safety of moxifloxacin vs levofloxacin in elderly patients hospitalized with community-acquired pneumonia. Chest 2005;128(5):3398-3406. [PubMed: 16304291]

34. Rubinstein E, Camm J. Cardiotoxicity of fluoroquinolones. J. Antimicrob Chemother 2002;49(4): 593-596. [PubMed: 11909831]

35. Feldman RB, Rhew DC, Wong JY, Charles RA, Goetz MB. Azithromycin monotherapy for patients hospitalized with community-acquired pneumonia: a 31/2-year experience from a veterans affairs hospital. Arch. Intern. Med 2003;163(14):1718-1726. [PubMed: 12885688]

36. Erard V, Lamy O, Bochud PY, Bille J, Cometta A, Calandra T. Full-course oral levofloxacin for treatment of hospitalized patients with community-acquired pneumonia. Eur. J. Clin. Microbiol. Infect. Dis 2004;23(2):82-88. [PubMed: 14727149]

37. Borrego F, Gleckman R. Principles of antibiotic prescribing in the elderly. Drugs Aging 1997;11(1):7-18. [PubMed: 9237037]

38. Bressler R, Bahl JJ. Principles of drug therapy for the elderly patient. Mayo Clin. Proc 2003;78(12):1564-1577. [PubMed: 14661688]

39. Rodriguez A, Mendia A, Sirvent JM, et al. Combination antibiotic therapy improves survival in patients with community-acquired pneumonia and shock. Crit. Care Med 2007;35(6):1493-1498. [PubMed: 17452932]

40. Baddour LM, Yu VL, Klugman KP, et al. Combination antibiotic therapy lowers mortality among severely ill patients with pneumococcal bacteremia. Am. J. Respir. Crit. Care Med 2004;170(4): 440-444. [PubMed: 15184200]

41. Martinez JA, Horcajada JP, Almela M, et al. Addition of a macrolide to a $\beta$-lactam-based empirical antibiotic regimen is associated with lower in-hospital mortality for patients with bacteremic pneumococcal pneumonia. Clin. Infect. Dis 2003;36(4):389-395. [PubMed: 12567294]

42. Lujan M, Gallego M, Fontanals D, Mariscal D, Rello J. Prospective observational study of bacteremic pneumococcal pneumonia: effect of discordant therapy on mortality. Crit. Care Med 2004;32(3):625-631. [PubMed: 15090938]

43. Waterer GW, Baselski VS, Wunderink RG. Legionella and community-acquired pneumonia: a review of current diagnostic tests from a clinician's viewpoint. Am. J. Med 2001;110(1):41-48. [PubMed: 11152864]

44. Mufson MA. Pneumococcal pneumonia. Curr. Infect. Dis. Rep 1999;1(1):57-64. [PubMed: 11095768]

45. Restrepo MI, Mortensen EM, Waterer GW, Wunderink RG, Coalson JJ, Anzueto A. Impact of macrolide therapy on mortality for patients with severe sepsis due to pneumonia. Eur. Respir. J 2009;33(1):153-159. [PubMed: 18768577] Retrospective cohort study that suggested that macrolide therapy was associated with lower mortality even in CAP patients even when CAP was caused by macrolide-resistant pneumonia pathogens. 
46. Giamarellos-Bourboulis EJ, Baziaka F, Antonopoulou A, et al. Clarithromycin co-administered with amikacin attenuates systemic inflammation in experimental sepsis with Escherichia coli. Int. J. Antimicrob. Agents 2005;25(2):168-172. [PubMed: 15664488]

47. Giamarellos-Bourboulis EJ. Immunomodulatory therapies for sepsis: unexpected effects with macrolides. Int. J. Antimicrob. Agents 2008;32 Suppl. 1:S39-S43. [PubMed: 18707849]

48. Metersky ML, Ma A, Houck PM, Bratzler DW. Antibiotics for bacteremic pneumonia: improved outcomes with macrolides but not fluoroquinolones. Chest 2007;131(2):466-473. [PubMed: 17296649]

49. Woodhead M, Blasi F, Ewig S, et al. Guidelines for the management of adult lower respiratory tract infections. Eur. Respir. J 2005;26(6):1138-1180. [PubMed: 16319346]

50. Mandell LA, Bartlett JG, Dowell SF, File TM Jr, Musher DM, Whitney C. Infectious Diseases Society of America: Update of practice guidelines for the management of community-acquired pneumonia in immunocompetent adults. Clin. Infect. Dis 2003;7(11):1405-1433. [PubMed: 14614663]

51. Niederman MS, Mandell LA, Anzueto A, et al. Guidelines for the management of adults with community-acquired pneumonia. diagnosis, assessment of severity, antimicrobial therapy, and prevention. Am. J. Respir. Crit. Care Med 2001;163(7):1730-1754. [PubMed: 11401897]

52. Bodi M, Rodriguez A, Sole-Violan J, et al. Antibiotic prescription for community-acquired pneumonia in the intensive care unit: impact of adherence to infectious diseases society of america guidelines on survival. Clin. Infect. Dis 2005;41(12):1709-1716. [PubMed: 16288392]

53. Dean NC, Silver MP, Bateman KA, James B, Hadlock CJ, Hale D. Decreased mortality after implementation of a treatment guideline for community-acquired pneumonia. Am. J. Med 2001;110(6):451-457. [PubMed: 11331056]

54. Garcia Vazquez E, Mensa J, Martinez JA, et al. Lower mortality among patients with communityacquired pneumonia treated with a macrolide plus a $\beta$-lactam agent versus a $\beta$-lactam agent alone. Eur. J. Clin. Microbiol. Infect. Dis 2005;24(3):190-195. [PubMed: 15782278]

55. Mortensen EM, Restrepo M, Anzueto A, Pugh J. Effects of guideline-concordant antimicrobial therapy on mortality among patients with community-acquired pneumonia. Am. J. Med 2004;117(10):726-731. [PubMed: 15541321]

56. Restrepo MI, Mortensen EM, Anzueto A, Pugh JA. Mortality in monotherapy versus combination therapy in severe community-acquired pneumonia: a systematic review. Chest 2003;124 Suppl. 4:S190.

57. Menendez R, Torres A, Zalacain R, et al. Guidelines for the treatment of community-acquired pneumonia: predictors of adherence and outcome. Am. J. Respir. Crit. Care Med 2005;172(6): 757-762. [PubMed: 15937289]

58. Confalonieri M, Urbino R, Potena A, et al. Hydrocortisone infusion for severe communityacquired pneumonia: a preliminary randomized study. Am. J. Respir. Crit. Care Med 2005;171(3): 242-248. [PubMed: 15557131]

59. Garcia-Vidal C, Calbo E, Pascual V, Ferrer C, Quintana S, Garau J. Effects of systemic steroids in patients with severe community-acquired pneumonia. Eur. Respir. J 2007;30(5):951-956. [PubMed: 17690125]

60. Laterre PF, Garber G, Levy H, et al. Severe community-acquired pneumonia as a cause of severe sepsis: data from the PROWESS study. Crit. Care Med 2005;33(5):952-961. [PubMed: 15891319]

61. The Acute Respiratory Distress Syndrome Network: Ventilation with lower tidal volumes as compared with traditional tidal volumes for acute lung injury and the acute respiratory distress syndrome. N. Engl. J. Med 2000;342(18):1301-1308. [PubMed: 10793162]

62. Tleyjeh IM, Kashour T, Hakim FA, et al. Statins for the prevention and treatment of infections: a systematic review and meta-analysis. Arch. Intern. Med 2009;169(18):658-1667.

63. Thomsen RW, Riis A, Kornum JB, et al. Preadmission use of statins and outcomes after hospitalization with pneumonia: population-based cohort study of 29,900 patients. Arch. Intern. Med 2008;168(19):2081-2087. [PubMed: 18955636]

64. Chalmers JD, Singanayagam A, Murray MP, Hill AT. Prior statin use is associated with improved outcomes in community-acquired pneumonia. Am. J. Med 2008;121(11):1002-1007. E1.

[PubMed: 18954848] 
65. Mortensen EM, Pugh MJ, Copeland LA, et al. Impact of statins and angiotensin-converting enzyme inhibitors on mortality of subjects hospitalised with pneumonia. Eur. Respir. J 2008;31(3): 611-617. [PubMed: 17959631]

66. Pavia M, Foresta MR, Carbone V, Angelillo IF. Influenza and pneumococcal immunization in the elderly: knowledge, attitudes, and practices among general practitioners in Italy. Public Health 2003;117(3):202-207. [PubMed: 12825471]

67. Huang YP, Gauthey L, Michel M, et al. The relationship between influenza vaccine-induced specific antibody responses and vaccine-induced nonspecific autoantibody responses in healthy older women. J. Gerontol 1992;47(2):M50-M55. [PubMed: 1538066]

68. Eurich DT, Marrie TJ, Johnstone J, Majumdar SR. Mortality reduction with influenza vaccine in patients with pneumonia outside 'flu' season: pleiotropic benefits or residual confounding? Am. J. Respir. Crit. Care Med 2008;178(5):527-533. [PubMed: 18556629]

69. Rubins JB, Alter M, Loch J, Janoff EN. Determination of antibody responses of elderly adults to all 23 capsular polysaccharides after pneumococcal vaccination. Infect. Immun 1999;67(11):5979_ 5984. [PubMed: 10531257]

70. Spaude KA, Abrutyn E, Kirchner C, Kim A, Daley J, Fisman DN. Influenza vaccination and risk of mortality among adults hospitalized with community-acquired pneumonia. Arch. Intern. Med 2007;167(1):53-59. [PubMed: 17210878]

71. Bassim CW, Gibson G, Ward T, Paphides BM, Denucci DJ. Modification of the risk of mortality from pneumonia with oral hygiene care. J. Am. Geriatr. Soc 2008;56(9):1601-1607. [PubMed: 18691286]

72. Panchabhai TS, Dangayach NS, Krishnan A, Kothari VM, Karnad DR. Oropharyngeal cleansing with $0.2 \%$ chlorhexidine for prevention of nosocomial pneumonia in critically ill patients: an open-label randomized trial with $0.01 \%$ potassium permanganate as control. Chest 2009;135(5): 1150-1156. [PubMed: 19420193]

\section{Website}

101. CDC guidelines for influenze. www.cdc.gov/flu 


\section{Table 1}

Pathogens associated with community-acquired pneumonia in elderly patients.

\begin{tabular}{|c|c|c|c|c|}
\hline Gram-positive cocci & $\begin{array}{l}\text { Gram-negative } \\
\text { bacilli }\end{array}$ & Atypical pathogens & Viral pathogens & Other \\
\hline Streptococcus pneumoniae & $\begin{array}{l}\text { Haemophilus } \\
\text { influenzae }\end{array}$ & Legionella species & $\begin{array}{l}\text { Influenza (e.g., H1N1 } \\
\text { and seasonal flu) }\end{array}$ & Anaerobes \\
\hline $\begin{array}{l}\text { Drug-resistant Streptococcus pneumoniae } \\
\text { (penicillin and macrolide resistant) }\end{array}$ & Escherichia coli & $\begin{array}{l}\text { Mycoplasma } \\
\text { pneumoniae }\end{array}$ & Parainfluenza & $\begin{array}{l}\text { Endemic and } \\
\text { opportunistic }\end{array}$ \\
\hline Staphylococcus aureus & Klebsiella species & $\begin{array}{l}\text { Chlamydophila } \\
\text { pneumoniae }\end{array}$ & $\begin{array}{l}\text { Severe acute } \\
\text { respiratory syndrome }\end{array}$ & $\begin{array}{l}\text { Mycobacterium } \\
\text { tuberculosis }\end{array}$ \\
\hline $\begin{array}{l}\text { Community-acquired methicillin-resistant } \\
\text { Staphylococcus aureus }\end{array}$ & $\begin{array}{l}\text { Pseudomonas } \\
\text { aeruginosa }\end{array}$ & - & - & $\begin{array}{l}\text { Nontuberculous } \\
\text { mycobacteria }\end{array}$ \\
\hline
\end{tabular}


Table 3

Scores developed to assess severity of illness in patients with severe community-acquired pneumonia and need for intensive care unit care.

\begin{tabular}{|c|c|c|c|}
\hline PS CURXO80 [29] & IDSA/ATS [24] & SMART-COP [30] & CAP-PIRO [31] \\
\hline 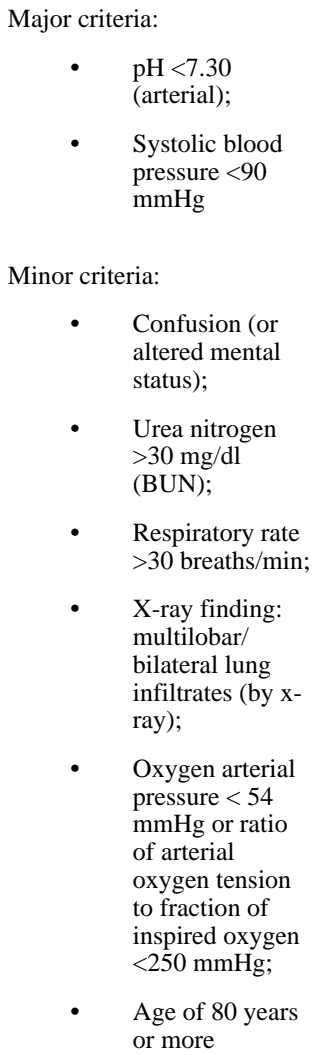 & 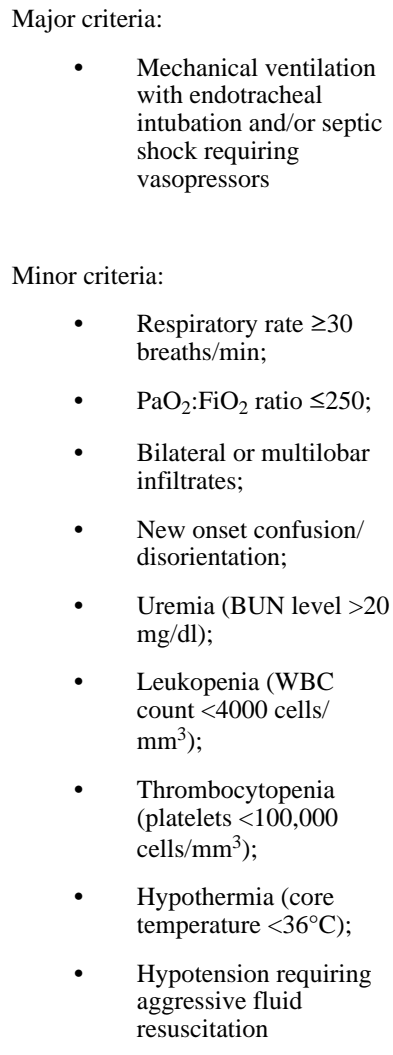 & $\begin{array}{l}\text { Systolic blood pressure low (1 } \\
\text { point); } \\
\text { Multilobar chest radiography } \\
\text { involvement ( } 1 \text { point); } \\
\text { Albumin level low (1 point), } \\
\text { high } \\
\text { Respiratory rate high (age- } \\
\text { adjusted; } \\
1 \text { point); } \\
\text { Tachycardia ( } 1 \text { point); } \\
\text { Confusion ( } 1 \text { point); } \\
\text { Oxygenation poor (age- } \\
\text { adjusted; } \\
2 \text { points); } \\
\text { pH arterial low (<7.35; } 2 \\
\text { points) }\end{array}$ & $\begin{array}{l}\text { Predisposition: comorbidities } \\
\text { (chronic } \\
\text { obstructive pulmonary disease or } \\
\text { immunocompromised; } 1 \text { point), age } \\
\text { > } 70 \text { years ( } 1 \text { point); } \\
\text { Infection; bacteremia ( } 1 \text { point), } \\
\text { multilobar } \\
\text { opacities ( } 1 \text { point); } \\
\text { Response: shock ( } 1 \text { point), severe } \\
\text { hypoxemia ( } 1 \text { point); and } \\
\text { Organ dysfunction: acute } \\
\text { respiratory } \\
\text { distress syndrome ( } 1 \text { point), acute } \\
\text { renal } \\
\text { failure ( } 1 \text { point) }\end{array}$ \\
\hline \multicolumn{4}{|l|}{ Interpretation } \\
\hline $\begin{array}{l}\text { At least one major criteria or } \\
\text { at least two } \\
\text { minor criteria from PS } \\
\text { CURXO80 defines } \\
\text { severe CAP and translate to } \\
\text { the need of } \\
\text { intermediate care or ICU } \\
\text { care. }\end{array}$ & $\begin{array}{l}\text { At least one major criteria or at } \\
\text { least three minor } \\
\text { criteria from IDSA/ATS define } \\
\text { severe CAP and } \\
\text { translate to the need of ICU care. }\end{array}$ & $\begin{array}{l}\text { A SMART-COP score of } \geq 3 \\
\text { points } \\
\text { identified } 92 \% \text { of patients who } \\
\text { received intensive respiratory } \\
\text { care or } \\
\text { vasopressor support, including } \\
84 \% \\
\text { of patients who did not need } \\
\text { immediate admission to the } \\
\text { ICU. }\end{array}$ & $\begin{array}{l}\text { Considering the observed mortality } \\
\text { from } \\
\text { each PIRO score, the patients were } \\
\text { stratified } \\
\text { in four levels of risk: low ( } 0-2 \\
\text { points); mild ( } 3 \text { points); high ( } 4 \\
\text { points); and } \\
\text { very high ( } 5-8 \text { points). The higher } \\
\text { the } \\
\text { score the higher the risk of } \\
\text { mortality, } \\
\text { prolonged length of stay in the ICU } \\
\text { and time } \\
\text { in days on mechanical ventilation. }\end{array}$ \\
\hline
\end{tabular}

ATS: American Thoracic Society; BUN: Blood urea nitrogen; CAP: Community-acquired pneumonia; ICU: Intensive care unit; IDST: Infectious Diseases Society of America; PIRO: Predisposition, infection, response and organ dysfunction score; PS CURXO80: pH, systolic blood pressure, confusion, urea nitrogen, respiratory rate, x-ray finding, oxygen arterial pressure and age of 80 years or more; SMART- COP: Systolic blood pressure, multilobar chest radiography, albumin level, respiratory rate, tachycardia, confusion, oxygenation and pH; WBC: White blood cell. 